\title{
Subclinical imaging changes in cerebral cavernous angiomas during prospective surveillance
}

\author{
*Julián Carrión-Penagos, MD, Hussein A. Zeineddine, MD, Sean P. Polster, MD, \\ Romuald Girard, PhD, Seán B. Lyne, BS, Janne Koskimäki, MD, PhD, Sharbel Romanos, BA, \\ Abhinav Srinath, BA, Dongdong Zhang, MD, Ying Cao, MSc, Agnieszka Stadnik, MS, \\ Kristina Piedad, BSN, Robert Shenkar, PhD, and Issam A. Awad, MD, MSc
}

Neurovascular Surgery Program, Section of Neurosurgery, Department of Surgery, The University of Chicago Medicine and Biological Sciences, Chicago, Illinois

OBJECTIVE The purpose of this study was to systematically assess asymptomatic changes (ACs), including subclinical hemorrhage, growth, or new lesion formation (NLF) during longitudinal follow-up of cerebral cavernous angiomas $(\mathrm{CAs})$, and to correlate these with symptomatic hemorrhage $(\mathrm{SH})$ during the same period and with clinical features of the disease.

METHODS One hundred ninety-two patients were included in this study, among 327 consecutive patients with CA, prospectively identified between September 2009 and February 2019. Included patients had undergone clinical and MRI follow-up, in conjunction with institutional review board-approved biomarker studies, and harbored $\geq 1 \mathrm{CA}$ with a maximum diameter of $\geq 5 \mathrm{~mm}$ on T2-weighted MRI. Rates of AC and SH per lesion-year and patient-year were assessed using prospectively articulated criteria. In multifocal/familial cases, rates of NLF were also assessed.

RESULTS There were no differences in demographic or disease features among cases included or excluded in the study cohort, except for a higher proportion of included patients with CCM3 mutation. Follow-up was 411 patient-years (2503 lesion-years). The rate of AC was higher than the rate of SH (12.9\% vs $7.5 \%$ per patient-year, and $2.1 \%$ vs $1.2 \%$ per lesion-year, both $p=0.02)$. Patients presenting with a prior history of $\mathrm{SH}$ had a higher rate of AC than those with other forms of presentation (19.7\% and $8.2 \%$ per patient-year, respectively; $p=0.003$ ). A higher rate of NLF on T2-weighted MRI $(p=0.03)$ was observed in patients with prior SH. Three of 6 solitary/sporadic and 2 of 28 multifocal/familial patients underwent resection of the lesion after AC.

CONCLUSIONS Rates of AC are greater than SH during prospective follow-up of CAs, and greater in cases with prior $\mathrm{SH}$. AC may be a more sensitive biomarker of lesional activity, and a more efficient surrogate outcome in clinical trials than SH. Patients experiencing an AC are more likely to undergo a surgical intervention when CAs are solitary/sporadic than when they are multifocal/familial.

https://thejns.org/doi/abs/10.3171/2020.1.JNS193479

KEYWORDS cerebral cavernous hemangioma; intracranial hemorrhage; cerebrovascular disorders; magnetic resonance imaging; natural history; vascular disorders

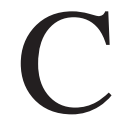
AVERNOUS angiomas (CAs) or cerebral cavernous malformations (CCMs), which affect $0.1 \%-0.5 \%$ of the American population, are abnormally clustered, dilated capillary caverns lined by a single layer of leaky endothelium and lacking mature vessel wall elements. ${ }^{1-3}$ Although they are low-flow vascular malforma- tions that are angiographically occult, ${ }^{4-6} \mathrm{CAs}$ can cause significant morbidity and mortality. Indeed, CAs predispose to a lifetime risk of symptomatic hemorrhage ( $\mathrm{SH}$ ) and other clinical sequelae. ${ }^{1,7,8}$ Symptoms are related to acute bleeding or iron deposition from chronic blood leakage. ${ }^{9}$ CAs can occur sporadically and are often associ-

ABBREVIATIONS $\mathrm{AC}=$ asymptomatic change; $\mathrm{CA}=$ cavernous angioma; $\mathrm{CCM}=$ cerebral cavernous malformation; $\mathrm{NLF}=$ new lesion formation; $\mathrm{SH}=$ symptomatic hemorrhage; SWI = susceptibility-weighted imaging.

SUBMITTED December 23, 2019. ACCEPTED January 28, 2020.

INCLUDE WHEN CITING Published online April 3, 2020; DOI: 10.3171/2020.1.JNS193479.

* J.C.P., H.A.Z., and S.P.P. contributed equally to this study. 
ated with a developmental venous anomaly. ${ }^{10} \mathrm{~A}$ familial form, which is less frequent, is inherited in an autosomal dominant fashion through one of three documented genes (KRIT1/CCM1, OSM/CCM2, and PDCD10/CCM3). ${ }^{3}$ Sporadic and familial CAs are histologically undistinguishable and harbor somatic mutations in the same CCM genes. ${ }^{11-14}$ The $C C M$ genes encode proteins involved in maintaining endothelial barrier integrity by inhibiting RhoA kinase (ROCK) activation. ${ }^{15,16}$

Meta-analyses of natural history studies have consistently identified a previous SH and brainstem lesion location as significant risk factors for future $\mathrm{SH} .{ }^{8,17,18} \mathrm{CAs}$ are known to undergo asymptomatic changes (ACs) on radiological imaging, ${ }^{19}$ but rates of these subclinical changes have not been systematically assessed in prospective studies. Such ACs have been associated with increased vascular permeability measured by dynamic contrast-enhanced quantitative perfusion, and iron deposits measured by quantitative susceptibility mapping on MRI, thereby reflecting underlying lesional biology. ${ }^{20}$

Here we conducted a prospective cohort study of patients with CA to assess patient-year and lesion-year rates of AC among consecutive cases with CA followed prospectively. We also assessed new lesion formation (NLF) in cases with multifocal/familial disease. These rates were compared to $\mathrm{SH}$ events during the same follow-up period, and correlated with initial clinical presentation, lesion location, and solitary/sporadic versus multifocal/familial disease. Finally, we assessed pragmatically how such changes on MRI influenced clinical management.

\section{Methods \\ Data Availability}

We agree to make available the data used to produce this manuscript for the purpose of reproducing the results, with the permission of the local IRB.

\section{Study Participants}

We reviewed our prospectively maintained CA database to identify eligible patients. Patients with a confirmed diagnosis of sporadic/solitary or multifocal/familial CA disease, and who had $\geq 1$ clinical follow-up visits with MRI data, were included in the study. All clinical evaluations were conducted at a single referral center (www. uchicagomedicine.org/ccm), where patients with CA disease are offered clinical and imaging follow-up in conjunction with IRB-approved biomarker studies. The senior author (I.A.A.) reviewed all MR images as part of the routine clinical care and adjudicated the entries in the database contemporaneously with each clinical visit. Routine MRI sequences included T2-weighted images, T1-weighted pre- and postcontrast images, T2*-weighted images, and susceptibility-weighted imaging (SWI) sequences performed on a 3T MRI scanner. Patients with sporadic disease who were referred for resection without further follow-up were excluded from the study. Patients with previous partial CA resection or any prior brain irradiation were also excluded. Two patients with familial disease, one with exceptional lesion burden ( $>100$ lesions on T2-weighted images), and the other with $>30$ NLF on
SWI sequences in a single year, were excluded as statistical outliers. Informed consent was obtained from all participants per IRB approval.

Clinical examination and MRI studies were typically performed at the initial visit, at 3 months, and then yearly thereafter in the absence of clinical symptoms. Earlier or more frequent follow-up studies were performed as clinically indicated if new symptoms occurred. Demographic information was collected in all patients including sex; age at diagnosis; age at first visit; mode of presentation (incidental, seizure, or SH); genotype; primary CA location; and number of lesions. Cases were categorized as solitary/ sporadic if they included a single lesion with or without clustered venous anomaly, and no family history. Cases were categorized as multifocal/familial if the patient harbored multifocal CAs, family history, or genotyped $C C M 1, C C M 2$, or $C C M 3$ germline mutation.

\section{Defining Lesion Location, SH, and AC on Radiological Imaging}

Lesions included for analysis were $\geq 5 \mathrm{~mm}$ at maximum width on $\mathrm{T} 2$-weighted sequences at initial scan. Location and number of CAs were recorded for each patient. CA locations were recorded as lobar, deep, cerebellar, or brainstem. The definition of SH required evidence of new bleeding on imaging studies and attributable clinical symptoms, as per published and widely accepted evidence-based criteria. ${ }^{19}$ Briefly, these include documentation of new clinical symptoms and imaging evidence of new bleeding or lesion expansion that can explain the symptoms. Imaging evidence includes acute or subacute bleeding on CT or MRI, new FLAIR signal on MRI, and/ or lesion expansion in any diameter by $\geq 3 \mathrm{~mm}$ on comparable T1- or T2-weighted sequences.

$\mathrm{AC}$ was defined as either lesional growth or new lesional hemorrhage. CA lesional growth was defined as an increase in any lesion diameter by $\geq 3 \mathrm{~mm}$ on comparable T1- or T2-weighted sequences (Fig. 1). Lesional growth was not assessed on SWI sequences because the blooming effect generates inaccurate readings for comparison. Patients with multifocal/familial disease were also assessed for the rate of NLF on follow-up MRI, based on lesion counts on SWI and T2-weighted sequences. ${ }^{21,22}$

\section{Statistical Analysis}

The rates of $\mathrm{SH}$ and $\mathrm{AC}$ were calculated per patientyear, and per lesion-year. The 2 rates were identical by definition in cases with solitary/sporadic lesions. The rate of NLF was also calculated in multifocal/familial cases. Rates and relative risks with $95 \%$ confidence intervals of $\mathrm{AC}$ and $\mathrm{SH}$ in patient-years and lesion-years were calculated according to initial clinical presentation and lesion location.

Sex, genotype, lesion location, mode of presentation, and the rate of $\mathrm{SH}, \mathrm{AC}$, and NLF were analyzed using a chi-square test or Fisher's exact test. Differences in age at inclusion were analyzed using a 2-sample t-test or an ANOVA for more than 2 groups. A p value $<0.05$ was considered statistically significant. SAS 9.4 (SAS Institute, Inc.) was used to conduct statistical analyses. 

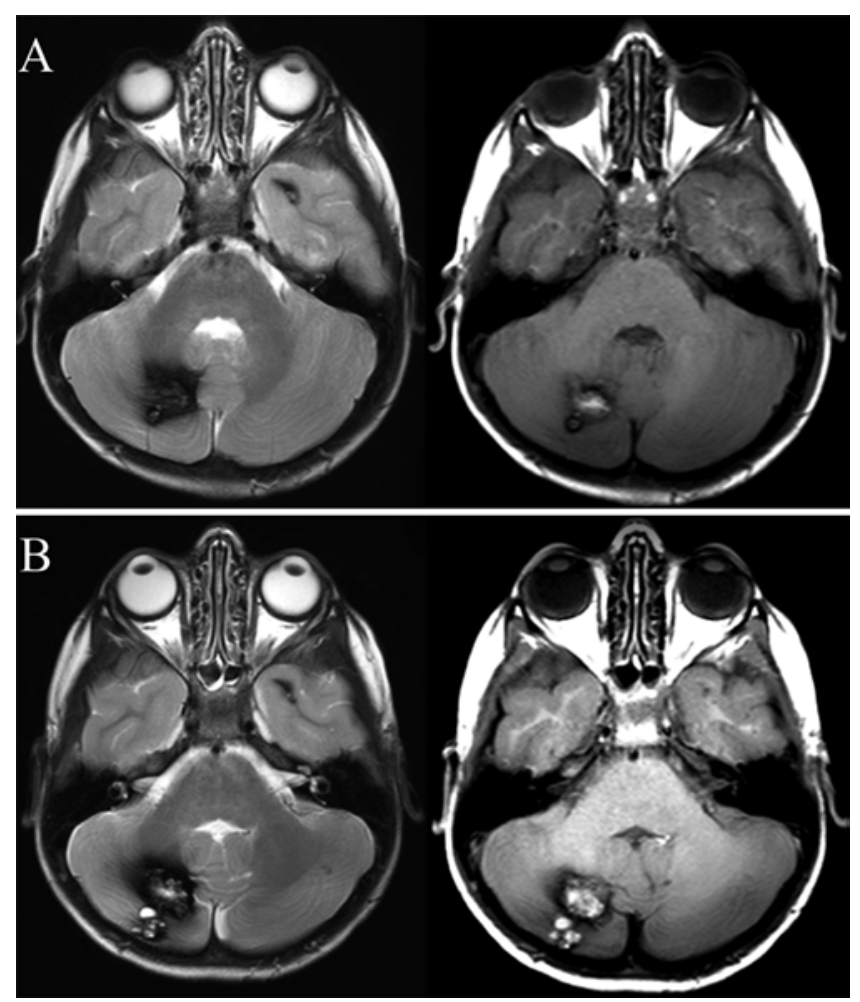

FIG. 1. Axial T1- (left-hand images) and T2- (right-hand images) weighted MR images showing a cerebellar CA lesion with the typical popcornlike appearance at baseline $(\mathbf{A})$ and after 1 year of follow-up (B) with demonstrated growth. The patient remained asymptomatic during this time period.

\section{Results}

\section{Demographics and Disease Characteristics}

Between September 2009 and February 2019, a total of 327 patients with CA were evaluated at our referral center, and 192 (harboring 885 lesions $\geq 5 \mathrm{~mm}$ at maximum diameter on T2-weighted sequences at initial scan) consented to participate in this IRB-approved study, met our inclusion/exclusion criteria, and had at least one clinical and imaging follow-up (Fig. 2). There was no difference between the cohorts of patients who were included and excluded, except for a higher rate of familial CCM3 genotype in the included patients (Supplemental Table 1). The patients were followed for a total of 411 patient-years (2503 lesion-years).

Table 1 presents demographic and disease features as well as numbers and rates of SH and AC. Patients who presented with $\mathrm{SH}$ were more likely to have a brainstem lesion compared to those with non-SH presentation ( $\mathrm{p}<$ $0.0001)$. In contrast, patients who were diagnosed incidentally or after a seizure were more likely to harbor a lobar lesion ( $p=0.003)$. The mean follow-up with clinical evaluation and imaging for all patients was 2.1 years, and the median follow-up with clinical evaluation and imaging for all patients was 1.6 years. Patients in the multifocal/familial group were followed for a significantly longer period compared to solitary/sporadic patients (median 2.0 vs 1.1 years; $\mathrm{p}=0.002$ ).

\section{SH and ACs}

Figure 3 presents the number of cases in various epochs of follow-up, and cases with events logged during those epochs. A total of $31 \mathrm{SHs}$ (in 30 lesions) occurred, with a rate of $7.5 \%$ per patient-year. Analysis of solitary/sporadic versus multifocal/familial cases is presented in Table 2 . A significantly higher rate of SH per patient-year was found in patients with multifocal/familial disease compared to solitary/sporadic cases $(10.4 \%$ vs $4.5 \%$; $p=0.04)$. Patients with solitary/sporadic disease had a significantly higher rate of SH in lesion-years compared to multifocal/familial cases $(4.5 \%$ vs $1.0 \% ; p=0.0006)$.

Fifty-three ACs (in 53 lesions) occurred during followup, with a rate of $12.9 \%$ per patient-year, significantly higher than the rate of SH (7.5\%) during the same period $(p=0.02)$. Rates of AC were also greater per lesion-year than SH (2.1\% vs $1.2 \%$; $p=0.02)$. Multifocal/familial cases had a higher rate of AC than solitary/sporadic cases in patient-years $(22.1 \%$ vs $3.0 \%$; $\mathrm{p}<0.0001)$ but not in lesionyears $(2.0 \%$ vs $3.0 \%$; $\mathrm{p}=0.31)$. Rates of $\mathrm{SH}$ and $\mathrm{AC}$ were not significantly different in males and females.

Patients presenting initially with SH had a higher rate per patient-year of both $\mathrm{AC}(\mathrm{p}=0.003)$ and $\mathrm{SH}(\mathrm{p}=0.03)$ than those presenting with seizures or incidentally (Table 1). Similarly, the rate of SH per lesion-year was significantly higher $(\mathrm{p}<0.0001)$ in lesions with previous $\mathrm{SH}$ compared to lesions with other forms of presentation. However, the rate of AC per lesion-year in those presenting with SH was not significantly different from those presenting incidentally or with seizures.

In cases with prior $\mathrm{SH}$, the rates of new $\mathrm{SH}$ and $\mathrm{AC}$ in patient-years and lesion-years were not significantly different in brainstem and nonbrainstem lesion location. In cases without prior $\mathrm{SH}$, those with brainstem lesions had a significantly higher rate of new SH and new AC in patientyears than those with nonbrainstem lesions (Table 3). The same was true in lesion-year analyses, with higher rates of SH and $\mathrm{AC}$ in brainstem cases presenting without $\mathrm{SH}$ (Table 4).

\section{New Lesion Formation}

During the follow-up period of 212 patient-years in patients with familial disease, 62 new lesions on SWI and 24 new lesions $\geq 5 \mathrm{~mm}$ maximum diameter on T2-weighted imaging were identified, representing rates of $29.2 \%$ and $11.3 \%$, respectively (Table 1). No differences in NLF were observed among genotypes, although the numbers of cases with each genotype were small (Supplemental Table 2).

Patients who had presented with SH had a significantly higher rate of NLF $\geq 5 \mathrm{~mm}$ maximum diameter on T2weighted images compared to those presenting with non$\mathrm{SH}(16.2 \%$ vs $5.3 \%, \mathrm{p}=0.03)$ (Table 1$)$. The rate of NLF on SWI was also higher, but not significantly different between patients with and without initial $\mathrm{SH}$ presentation (34.0\% and 23.2\%).

\section{Impact on Clinical Management}

Nine of 24 patients (37.5\%) with new SH during followup underwent resection of the hemorrhagic lesion. These included $75 \%$ of sporadic cases and $18.75 \%$ of familial 


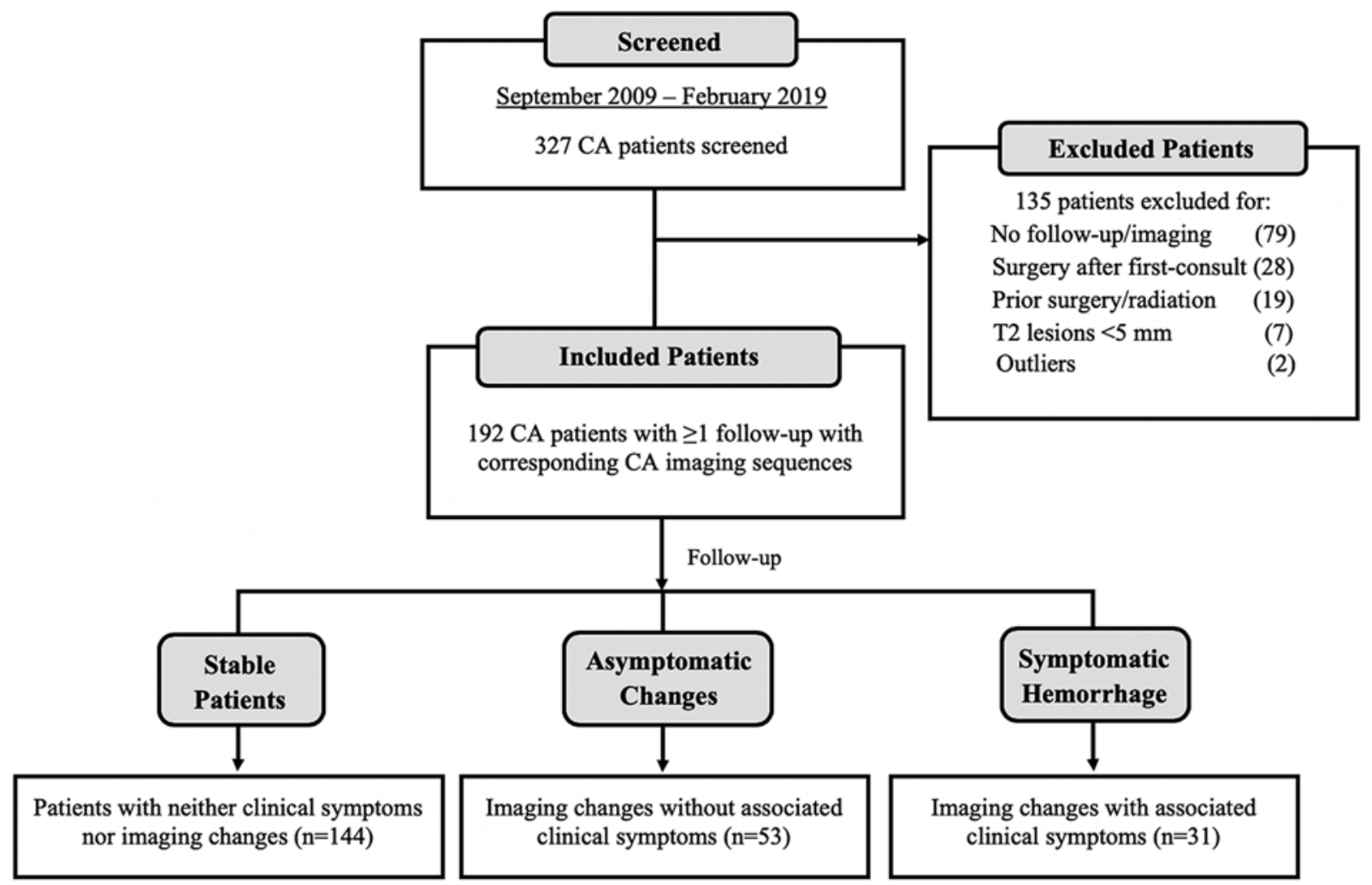

FIG. 2. CONSORT diagram of included and excluded patients. Between September 2009 and February 2019, 327 patients with $\mathrm{CAs}$, either solitary/sporadic or multifocal/familial, were screened. One hundred thirty-five patients were excluded from our study. One hundred ninety-two patients were included, of whom 144 did not have clinical or radiological changes during the follow-up period. There were $53 \mathrm{ACs}$ in 34 patients, and $31 \mathrm{SHs}$ in 24 patients. Some patients had both AC and SH events. In the diagram, $\mathrm{n}$ refers to the number of $\mathrm{AC}$ or $\mathrm{SH}$ events.

patients with $\mathrm{SH}$, respectively $(\mathrm{p}=0.02)$. Five of 34 cases $(14.7 \%)$ with $\mathrm{AC}$ underwent resection, after consideration of all options and risks. These included 3 of $6(50 \%)$ solitary/sporadic cases and 2 of $28(7.1 \%)$ patients with multifocal/familial disease $(\mathrm{p}=0.03)$. Reasons for surgery in the 3 solitary/sporadic cases included the desire to cure a growing lesion and confirm histological diagnosis (rule out neoplasm). In the 2 familial cases, the lesion growth was major (by $>1 \mathrm{~cm}$ ) in one case, and included repetitive ACs in the second case.

\section{Discussion}

The natural course of CAs has been widely studied. Earlier reports included various definitions of outcome events and a heterogeneous description of hemorrhages., ${ }^{7,23}$ Confusion often arose about what might constitute a lesional hemorrhage, given the evidence of chronic bleeding in every CA lesion on imaging and pathology. ${ }^{1-3}$ More recently, a standardized definition of SH was articulated, requiring evidence of new bleeding on diagnostic studies and attributable new clinical manifestations. ${ }^{19}$ Subsequent studies considering this definition have consistently identified a prior $\mathrm{SH}$ and a brainstem lesion location as risk factors of recurrent $\mathrm{SH}^{8,17,18}$

Although asymptomatic hemorrhages and lesional growth have been known to occur in $\mathrm{CAs},{ }^{19}$ their rates have never been systematically assessed. This is largely in view of inconsistent recommendations of clinical and imaging surveillance in asymptomatic lesions. ${ }^{1}$ Routine follow-up in clinical practice is dependent on insurance, patient preferences, and neurological and/or neurosurgical practitioners' practice standards. Repeat imaging may be precipitated by changes in neurological status, in particular the development of new neurological symptoms suggestive of CA hemorrhage, changed or worsening epilepsy, or changes in neurological signs on examination. Follow-up imaging may also be inconsistently considered to reassure patients about stability of CAs with respect to lifestyle, medications, pregnancy, or nonspecific symptoms. With the establishment of CA registries at Angioma Alliance-designated Centers of Excellence (www. angioma.org), harmonized data entry in trial readiness initiatives, ${ }^{24}$ and more frequent follow-up of cases in conjunction with biomarker studies, ${ }^{20}$ an opportunity arose to assess rates of $\mathrm{AC}$ during systematic prospective surveillance of CAs.

Rates of ACs were significantly higher than (almost double) the rates of $\mathrm{SH}$ per patient-year and lesion-year during the same follow-up of CAs. Although this has never been reported previously, it should not be surprising, because many CA lesions arise in noneloquent lesion locations, where a hemorrhage might not result in overt symptoms. Also not surprising are our findings that most of the 
TABLE 1. Demographic data, SHs, ACs, and NLF according to clinical presentation

\begin{tabular}{|c|c|c|c|c|}
\hline \multirow[b]{2}{*}{ Characteristic } & \multicolumn{3}{|c|}{ Clinical Presentation Leading to CCM Diagnosis } & \multirow[b]{2}{*}{ p Value* } \\
\hline & Incidental \& Seizure $(n=118)$ & $\mathrm{SH}(\mathrm{n}=74)$ & Total $(n=192)$ & \\
\hline Age at diagnosis, yrs (range) & $37.7 \pm 18.0(0.5-76)$ & $33.7 \pm 20.1(0.3-72)$ & $36.2 \pm 18.9(0.3-76)$ & 0.2 \\
\hline Age at first visit, yrs (range) & $41.7 \pm 17.7(4-80)$ & $38.5 \pm 19.2(1-72)$ & $40.5 \pm 18.3(1-80)$ & 0.2 \\
\hline \multicolumn{5}{|l|}{ Sex } \\
\hline Male & $27(22.9 \%)$ & $29(39.2 \%)$ & $56(29.2 \%)$ & 0.1 \\
\hline Female & $91(77.1 \%)$ & $45(60.8 \%)$ & $136(70.8 \%)$ & 0.3 \\
\hline \multicolumn{5}{|l|}{ Genotype } \\
\hline Sporadic/solitary & $75(63.6 \%)$ & $33(44.6 \%)$ & $108(56.3 \%)$ & 0.2 \\
\hline \multicolumn{5}{|l|}{ Familial/multifocal } \\
\hline CCM1 & $12(10.2 \%)$ & $15(20.3 \%)$ & $27(14.1 \%)$ & 0.1 \\
\hline CCM2 & $7(5.9 \%)$ & $3(4.1 \%)$ & $10(5.2 \%)$ & 0.7 \\
\hline CCM3 & $10(8.5 \%)$ & $12(16.2 \%)$ & $22(11.5 \%)$ & 0.2 \\
\hline Multifocal unknown genotype & $14(11.9 \%)$ & $11(14.9 \%)$ & $25(13.0 \%)$ & 0.6 \\
\hline \multicolumn{5}{|l|}{ Primary CCM location† } \\
\hline Lobar & $72(61.0 \%)$ & $19(25.7 \%)$ & $91(47.4 \%)$ & 0.003 \\
\hline Deep & $20(17.0 \%)$ & $10(13.5 \%)$ & $30(15.6 \%)$ & 0.6 \\
\hline Cerebellar & $13(11.0 \%)$ & $3(4.1 \%)$ & $16(8.3 \%)$ & 0.1 \\
\hline Brainstem & $13(11.0 \%)$ & $42(56.8 \%)$ & $55(28.7 \%)$ & $<0.0001$ \\
\hline \multicolumn{5}{|l|}{ No. of $A C \& S H$} \\
\hline $\mathrm{AC}$ & 20 & 33 & 53 & \\
\hline $\mathrm{SH}$ & 12 & 19 & 31 & \\
\hline \multicolumn{5}{|l|}{ Total follow-up } \\
\hline Patient-years & 244.0 & 167.7 & 411.7 & \\
\hline Lesion-years & 2338.6 & 164.7 & 2503.3 & \\
\hline \multicolumn{5}{|l|}{ Rate in patient-years $(95 \% \mathrm{Cl})$} \\
\hline $\mathrm{AC}$ & $8.2 \%(5.4-12.5)$ & $19.7 \%(15.0-26.7)$ & $12.9 \%(10.0-16.6)$ & 0.003 \\
\hline $\mathrm{SH}$ & $4.9 \%(2.8-8.5)$ & $11.3 \%(7.4-17.3)$ & $7.5 \%(5.4-10.6)$ & 0.03 \\
\hline \multicolumn{5}{|l|}{ Rate in lesion-years $(95 \% \mathrm{Cl})$} \\
\hline $\mathrm{AC}$ & $2.1 \%(1.6-2.7)$ & $3.0 \%(1.3-7.2)$ & $2.1 \%(1.6-2.8)$ & 0.4 \\
\hline $\mathrm{SH}$ & $0.7 \%(0.4-1.1)$ & $9.1 \%(5.6-14.8)$ & $1.2 \%(0.9-1.8)$ & $<0.0001$ \\
\hline \multicolumn{5}{|l|}{ NLF } \\
\hline SWI & 22 & 40 & 62 & \\
\hline T2-weighted imaging & 5 & 19 & 24 & \\
\hline \multicolumn{5}{|c|}{ Rate of NLF in familial/multifocal cases $(95 \% \mathrm{Cl})$} \\
\hline SWI & $23.2 \%(16.1-33.5)$ & $34.0 \%(26.5-43.8)$ & $29.2 \%(23.7-36.0)$ & 0.2 \\
\hline T2-weighted imaging & $5.3 \%(2.2-12.4)$ & $16.2 \%(10.7-24.4)$ & $11.3 \%(7.8-16.5)$ & 0.03 \\
\hline
\end{tabular}

* Comparison between patients with $\mathrm{SH}$ and those presenting incidentally or with seizures.

$\dagger$ In cases with multiple lesions, the symptomatic lesion was considered primary, and the largest lesion was considered primary if all were asymptomatic.

patients with $\mathrm{SH}$ at initial presentation had a brainstem lesion, whereas patients who were diagnosed after seizure or incidentally had predominantly lobar lesions. And as with previous studies, we found that patients with initial SH presentation had higher rates of subsequent $\mathrm{SH} .{ }^{8,17,18}$ We now showed that patients with initial SH presentation also had greater rates of AC. Rates of AC per patient-year were significantly greater in multifocal/familial cases than in solitary/sporadic cases, consistent with a greater number of lesions in the former. Rates of AC per lesion-year were not different in multifocal/familial and solitary/sporadic lesions.
Rates of $\mathrm{AC}$ were consistently greater than rates of $\mathrm{SH}$ regardless of lesion location and initial presentation. Among cases with non-SH presentation, those with a brainstem lesion had a significantly higher risk of future SH and AC compared to nonbrainstem lesions. The higher risks of $\mathrm{AC}$ and $\mathrm{SH}$ in cases with initial $\mathrm{SH}$ presentation and brainstem lesion location indicate that $\mathrm{AC}$ and $\mathrm{SH}$ reflect similar biological propensities. The rate of future $\mathrm{SH}$ or AC in patients with initial SH presentation did not seem to be affected by the location of the lesion, perhaps indicating that prior $\mathrm{SH}$ is a more dominant predictor of new $\mathrm{SH}$ and $\mathrm{AC}$ than lesion location. 


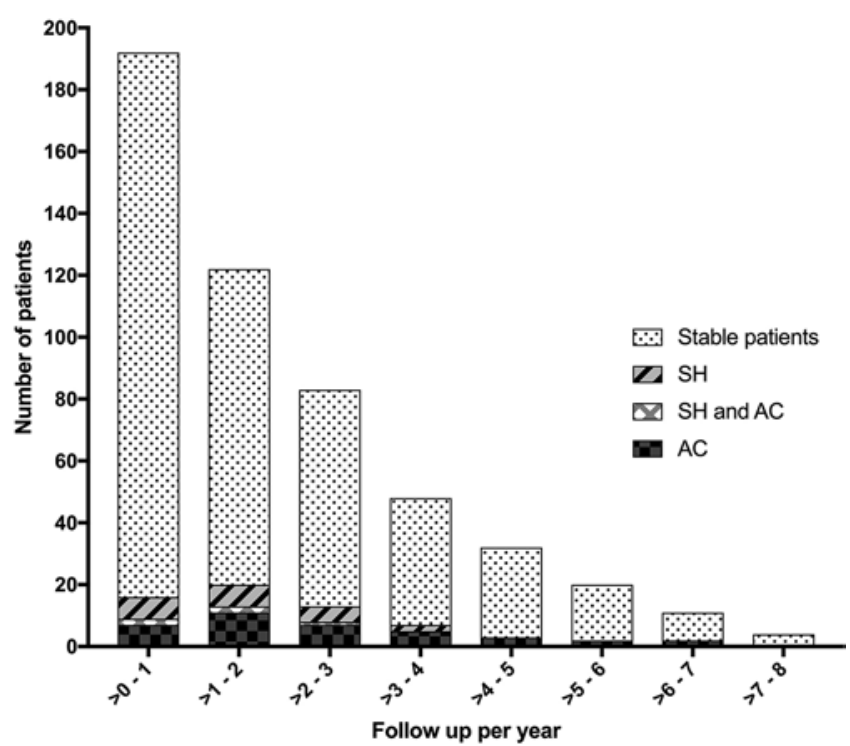

FIG. 3. Histogram including the number of cases during various epochs of prospective follow-up surveillance, and the number of cases with $\mathrm{SH}$ and $A C$ logged during each epoch.

The combined rates of $\mathrm{SH}$ and $\mathrm{AC}$ are nearly 3 times those of $\mathrm{SH}$ alone. This raises an interesting proposition: that of using the combined rate as a more sensitive/ efficient surrogate outcome of lesional bleeding than $\mathrm{SH}$ alone. This would allow smaller sample sizes in proof-ofconcept trials of emerging therapies aimed at decreasing lesional bleeding. ${ }^{24}$ Future studies should also examine $\mathrm{AC}$ in relation to emerging plasma biomarkers of lesional hemorrhage. ${ }^{25}$

Rates of NLF had previously been estimated in multifocal/familial CA cases, ${ }^{1}$ including higher rates with $C C M 3$ genotype. ${ }^{26}$ We now show that patients with previous $\mathrm{SH}$ were found to have higher rates of NLF-including, significantly, the larger lesions on T2-weighted images that are more likely to cause clinical sequelae. We had previously shown that NLF occurs in brain regions with higher vascular permeability on dynamic contrast-enhanced quantitative perfusion MRI. ${ }^{20}$ Together, these observations suggest that NLF may serve as an indication of overall disease instability.

We analyzed empirically whether SH or AC influenced the decision-making process in the clinic. Patients with sporadic disease were more likely to undergo resection of a lesion with an $\mathrm{SH}$ or $\mathrm{AC}$ in comparison to familial cases. The lower threshold for surgical intervention in the group
TABLE 2. ACs and SHs in patients with solitary/sporadic and multifocal/familial disease

\begin{tabular}{|c|c|c|c|}
\hline Variable & $\begin{array}{l}\text { Solitary/ } \\
\text { Sporadic }\end{array}$ & $\begin{array}{l}\text { Multifocal/ } \\
\text { Familial }\end{array}$ & $\begin{array}{c}\mathrm{p} \\
\text { Value }\end{array}$ \\
\hline No. of patients & 108 & 84 & \\
\hline \multicolumn{4}{|c|}{$\begin{array}{l}\text { No. of patients w/ ACs } \\
\& \text { SHs (no. of lesions) }\end{array}$} \\
\hline $\mathrm{AC}$ & $6(6)$ & $47(47)$ & \\
\hline $\mathrm{SH}$ & $9(8)$ & $22(22)$ & \\
\hline \multicolumn{4}{|l|}{ Total follow-up } \\
\hline Patient-year & 199.4 & 212.3 & \\
\hline Lesion-year & 199.4 & 2303.9 & \\
\hline \multicolumn{4}{|c|}{$\begin{array}{l}\text { Rate in patient-years } \\
(95 \% \mathrm{Cl})\end{array}$} \\
\hline $\mathrm{AC}$ & $3.0 \%(1.4-6.6)$ & $22.1 \%(17.2-28.5)$ & $<0.0001$ \\
\hline $\mathrm{SH}$ & $4.5 \%(2.4-8.6)$ & $10.4 \%(7.0-15.4)$ & 0.04 \\
\hline \multicolumn{4}{|c|}{$\begin{array}{l}\text { Rate in lesion-years } \\
(95 \% \mathrm{Cl})\end{array}$} \\
\hline $\mathrm{AC}$ & $3.0 \%(1.4-6.6)$ & $2.0 \%(1.5-2.7)$ & 0.3 \\
\hline $\mathrm{SH}$ & $4.5 \%(2.4-8.6)$ & $1.0 \%(0.6-1.5)$ & 0.0006 \\
\hline
\end{tabular}

with sporadic disease may be related to the curative nature of the intervention and the avoidance of future risk of $\mathrm{SH}$ in an unstable lesion, symptoms of mass effect from a growing lesion, and even a remote possibility of neoplasia rather than CA. Conversely, there was greater equipoise with regard to resecting a lesion exhibiting subclinical imaging changes in patients with familial disease who harbor many lesions, in whom resecting any single lesion is less likely to influence the patient's future life and care.

We admittedly did not study the natural history of AC, including prospective risks of SH after an AC. The numbers and follow-ups of those cases were limited, and biased by a high rate of intervention, particularly in solitary/ sporadic cases. We cannot prove that an approach of acting on $\mathrm{AC}$, including consideration of surgery, is beneficial to patients. In fact, a recent study from a European center concluded that regular follow-up imaging of asymptomatic CA patients had no influence on surgical decisionmaking. ${ }^{27}$ However, the rate of ACs and their implications were not assessed in that study, and both our conclusions and theirs remain circuitous, reflecting options of followup surveillance of asymptomatic lesions, or lack thereof. Only a prospective randomized study on surveillance strategy and clinical outcomes can settle this controversy.

TABLE 3. Rates of SH and AC in patient-years according to clinical presentation and location of index lesion

\begin{tabular}{lcccccc}
\hline Presentation, Location & No. of Patients & Patient-Years & $\mathrm{SH}$ & Rate of SH $(95 \% \mathrm{Cl})$ & $\mathrm{AC}$ & Rate of AC $(95 \% \mathrm{Cl})$ \\
\hline SH, brainstem & 42 & 98.2 & 10 & $10.2 \%(5.7-18.3)$ & 14 & $14.3 \%(8.8-23.2)$ \\
\hline SH, nonbrainstem & 32 & 69.5 & 9 & $12.9 \%(7.0-23.8)$ & 19 & $27.3 \%(18.6-40.1)$ \\
\hline Non-SH, brainstem & 13 & 23.3 & 4 & $17.1 \%(7.0-41.8)^{*}$ & 8 & $34.3 \%(19.5-60.1)^{*}$ \\
\hline Non-SH, nonbrainstem & 105 & 220.7 & 8 & $3.6 \%(1.8-7.2)^{*}$ & 12 & $5.4 \%(3.1-9.4)^{*}$ \\
\hline
\end{tabular}

${ }^{*}$ Values are statistically significantly different $(p<0.05)$. 
TABLE 4. Rates of SH and AC in lesion-years according to clinical presentation and location of index lesion

\begin{tabular}{lcrrrrc}
\hline Presentation, Location & No. of Patients & Lesion-Years & SH & Rate of SH $(95 \% \mathrm{Cl})$ & $\mathrm{AC}$ & Rate of AC (95\% Cl) \\
\hline SH, brainstem & 42 & 104.4 & 7 & $6.7 \%(3.3-13.7)$ & 3 & $2.9 \%(0.9-8.8)$ \\
\hline SH, nonbrainstem & 32 & 60.3 & 8 & $13.3 \%(7.0-25.3)$ & 2 & $3.3 \%(0.8-13.0)$ \\
\hline Non-SH, brainstem & 13 & 66.4 & 15 & $7.5 \%(3.2-17.5)^{*}$ & 8 & $12.1 \%(6.3-23.1)^{*}$ \\
\hline Non-SH, nonbrainstem & 105 & 2272.2 & 11 & $0.5 \%(0.3-0.9)^{*}$ & 40 & $1.8 \%(1.3-2.4)^{*}$ \\
\hline
\end{tabular}

* Values are statistically significantly different $(p<0.05)$.

Our results do not change current levels of evidence about options of prospective surveillance in clinical practice, nor decisions about surgery. ${ }^{1}$ The combined rate of SH and AC during prospective surveillance is approximately 3-fold the rate of SH alone. Hence, the combined rate may be a more sensitive endpoint in clinical trials.

Admittedly, our rates of AC were based on a policy of annual surveillance, and may have missed subclinical events that could have occurred between imaging sessions. Rates of AC would probably be greater with more frequent imaging. Other limitations of this study include its single site, with inherent referral biases, and the exclusion of many patients due to a lack of follow-up. However, we showed no significant confounders between included and excluded cases. Also, our large cohort of patients with CAs undergoing regular surveillance in conjunction with biomarker studies represented a unique opportunity to address a previous knowledge gap in this disease. We hope that these results will generate novel hypotheses to be tested in future studies including multisite or populationbased enrollments, time-to-event analyses, and correlations with surgical decisions.

\section{Conclusions}

We report for the first time the rate of $\mathrm{AC}$, which is significantly more common than $\mathrm{SH}$ during prospective follow-up of patients with $\mathrm{CA}$. Both $\mathrm{AC}$ and $\mathrm{SH}$ are more common in patients with previous $\mathrm{SH}$ and with brainstem lesions, indicating that they both reflect similar disease instability. Together, they may provide a more sensitive combined surrogate outcome for biomarker development and proof-of-concept trials of therapies aimed at CA hemorrhage. Although ACs influence clinical decisions in empirical clinical practice, particularly the curative resection of solitary lesions, our results do not change the levels of evidence of current recommendations for surgical treatment of CAs. ${ }^{1}$

\section{Acknowledgments}

This work was partially supported by a grant from the NIH (R21NS087328) to Dr. Awad; the William and Judith Davis Fund in Neurovascular Surgery Research and the Safadi Translational Fellowship to Dr. Girard; and the Sigrid Juselius Foundation, Maud Kuistila Foundation, and Emil Aaltonen Foundation to Dr. Koskimäki.

\section{References}

1. Akers A, Al-Shahi Salman R, Awad IA, et al. Synopsis of Guidelines for the Clinical Management of Cerebral Cavern- ous Malformations: Consensus Recommendations Based on Systematic Literature Review by the Angioma Alliance Scientific Advisory Board Clinical Experts Panel. Neurosurgery. 2017;80(5):665-680.

2. Al-Holou WN, O'Lynnger TM, Pandey AS, et al. Natural history and imaging prevalence of cavernous malformations in children and young adults. J Neurosurg Pediatr. 2012;9(2):198-205.

3. Awad IA, Polster SP. Cavernous angiomas: deconstructing a neurosurgical disease. J Neurosurg. 2019;131(1):1-13.

4. Robinson JR Jr, Awad IA, Masaryk TJ, Estes ML. Pathological heterogeneity of angiographically occult vascular malformations of the brain. Neurosurgery. 1993;33(4):547-555.

5. Shimizu Y, Sasaki K, Ujiie H, et al. Pathological findings of angiographically occult vascular malformation. J Clin Neurosci. 2002;9(suppl 1):19-21.

6. Tomlinson FH, Houser OW, Scheithauer BW, et al. Angiographically occult vascular malformations: a correlative study of features on magnetic resonance imaging and histological examination. Neurosurgery. 1994;34(5):792-800.

7. Al-Shahi Salman R, Hall JM, Horne MA, et al. Untreated clinical course of cerebral cavernous malformations: a prospective, population-based cohort study. Lancet Neurol. 2012;11(3):217-224.

8. Horne MA, Flemming KD, Su IC, et al. Clinical course of untreated cerebral cavernous malformations: a meta-analysis of individual patient data. Lancet Neurol. 2016;15(2):166-173.

9. Baumann CR, Schuknecht B, Lo Russo G, et al. Seizure outcome after resection of cavernous malformations is better when surrounding hemosiderin-stained brain also is removed. Epilepsia. 2006;47(3):563-566.

10. Petersen TA, Morrison LA, Schrader RM, Hart BL. Familial versus sporadic cavernous malformations: differences in developmental venous anomaly association and lesion phenotype. AJNR Am J Neuroradiol. 2010;31(2):377-382.

11. Akers AL, Johnson E, Steinberg GK, et al. Biallelic somatic and germline mutations in cerebral cavernous malformations (CCMs): evidence for a two-hit mechanism of CCM pathogenesis. Hum Mol Genet. 2009;18(5):919-930.

12. Gault J, Awad IA, Recksiek P, et al. Cerebral cavernous malformations: somatic mutations in vascular endothelial cells. Neurosurgery. 2009;65(1):138-145.

13. Gault J, Shenkar R, Recksiek P, Awad IA. Biallelic somatic and germ line CCM1 truncating mutations in a cerebral cavernous malformation lesion. Stroke. 2005;36(4):872-874.

14. McDonald DA, Shi C, Shenkar R, et al. Lesions from patients with sporadic cerebral cavernous malformations harbor somatic mutations in the CCM genes: evidence for a common biochemical pathway for CCM pathogenesis. Hum Mol Genet. 2014;23(16):4357-4370.

15. Stockton RA, Shenkar R, Awad IA, Ginsberg MH. Cerebral cavernous malformations proteins inhibit Rho kinase to stabilize vascular integrity. J Exp Med. 2010;207(4):881-896.

16. Whitehead KJ, Chan AC, Navankasattusas S, et al. The cerebral cavernous malformation signaling pathway promotes vascular integrity via Rho GTPases [erratum in: Nat Med. 2009;15(4):462]. Nat Med. 2009;15(2):177-184. 
17. Gross BA, Du R. Hemorrhage from cerebral cavernous malformations: a systematic pooled analysis. J Neurosurg. 2017;126(4):1079-1087.

18. Taslimi S, Modabbernia A, Amin-Hanjani S, et al. Natural history of cavernous malformation: systematic review and meta-analysis of 25 studies. Neurology. 2016;86(21):19841991.

19. Al-Shahi Salman R, Berg MJ, Morrison L, Awad IA. Hemorrhage from cavernous malformations of the brain: definition and reporting standards. Stroke. 2008;39(12):3222-3230.

20. Girard R, Fam MD, Zeineddine HA, et al. Vascular permeability and iron deposition biomarkers in longitudinal follow-up of cerebral cavernous malformations. J Neurosurg. 2017:127(1):102-110.

21. de Champfleur NM, Langlois C, Ankenbrandt WJ, et al. Magnetic resonance imaging evaluation of cerebral cavernous malformations with susceptibility-weighted imaging. Neurosurgery. 2011;68(3):641-648.

22. de Souza JM, Domingues RC, Cruz LC Jr, et al. Susceptibility-weighted imaging for the evaluation of patients with familial cerebral cavernous malformations: a comparison with T2-weighted fast spin-echo and gradient-echo sequences. AJNR Am J Neuroradiol. 2008;29(1):154-158.

23. Labauge P, Brunereau L, Laberge S, Houtteville JP. Prospective follow-up of 33 asymptomatic patients with familial cerebral cavernous malformations. Neurology. 2001;57(10):1825-1828.

24. Polster SP, Cao Y, Carroll T, et al. Trial readiness in cavernous angiomas with symptomatic hemorrhage (CASH). Neurosurgery. 2019;84(4):954-964.

25. Lyne SB, Girard R, Koskimäki J, et al. Biomarkers of cavernous angioma with symptomatic hemorrhage. JCI Insight. 2019;4(12):4

26. Shenkar R, Shi C, Rebeiz T, et al. Exceptional aggressiveness of cerebral cavernous malformation disease associated with PDCD10 mutations. Genet Med. 2015;17(3):188-196.

27. Velz J, Stienen MN, Neidert MC, et al. Routinely performed serial follow-up imaging in asymptomatic patients with mul- tiple cerebral cavernous malformations has no influence on surgical decision making. Front Neurol. 2018;9:848.

\section{Disclosures}

The authors report no conflict of interest concerning the materials or methods used in this study or the findings specified in this paper.

\section{Author Contributions}

Conception and design: Awad. Acquisition of data: Awad, Carrión-Penagos, Zeineddine, Polster, Girard, Lyne, Koskimäki, Romanos, Zhang, Stadnik, Piedad. Analysis and interpretation of data: Awad, Carrión-Penagos, Girard. Drafting the article: Awad, Carrión-Penagos, Zeineddine, Polster, Girard, Lyne, Koskimäki, Srinath. Critically revising the article: Awad, Girard, Shenkar. Reviewed submitted version of manuscript: Awad, Shenkar. Statistical analysis: Cao. Study supervision: Awad.

\section{Supplemental Information}

Online-Only Content

Supplemental material is available with the online version of the article.

Supplementary Tables 1 and 2. https://thejns.org/doi/suppl/10. 3171/2020.1.JNS193479.

\section{Previous Presentations}

Part of the material in this paper was presented in poster form at the American Association of Neurological Surgeons Annual Meeting in Los Angeles, California, April 2017.

\section{Correspondence}

Issam A. Awad: University of Chicago Medicine, Chicago, IL. iawad@uchicago.edu. 